\title{
Detection and Prevention of Plagiarism in Higher Education
}

\author{
Carlos Cortinhas[i] \\ The University of Exeter, UK and \\ The Economic Policies Research Unit (NIPE), \\ The University of Minho, Portugal \\ c.cortinhas@exeter.ac.uk
}

\section{Contents}

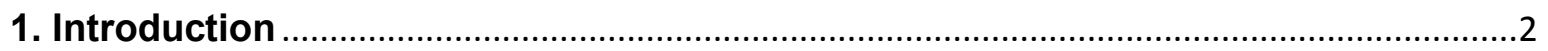

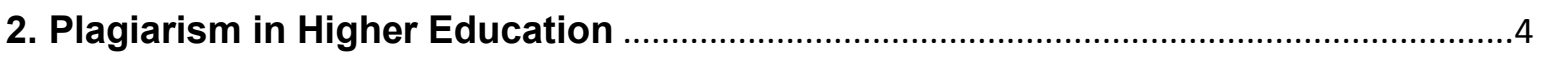

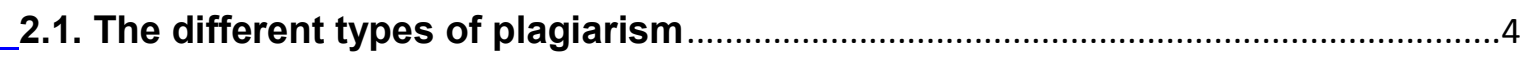

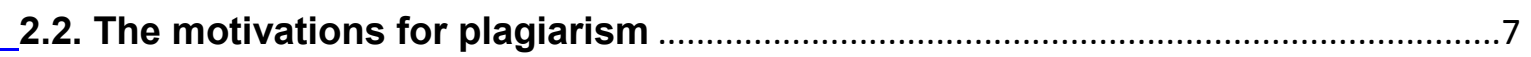

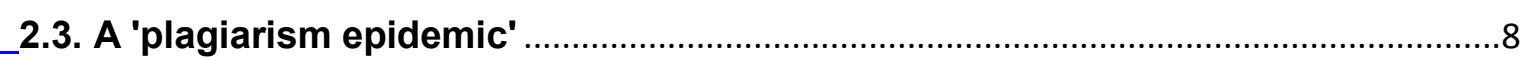

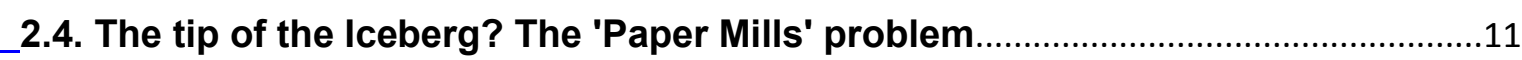

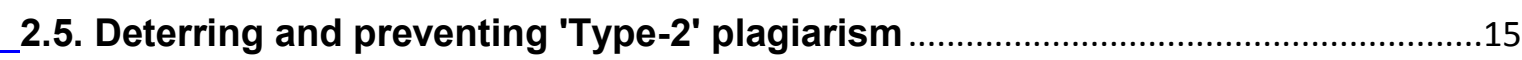

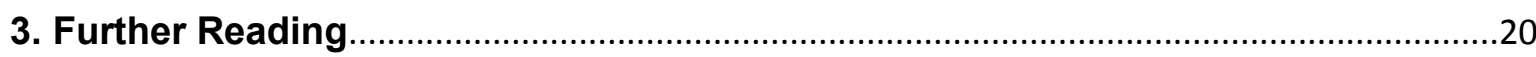

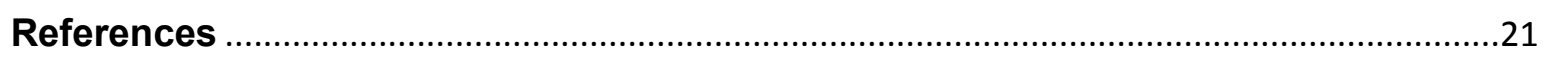

\section{Notes}

[i] The usual disclaimer applies.

[ii] This chapter builds on (and extends) a previous version written by Jeremy B. Williams entitled Plagiarism: Deterrence, Detection and Prevention which was written for the Economics Network in 2005. 


\section{Introduction}

Charles Caleb Colton once observed that 'imitation is the sincerest form of flattery'. Whilst this may be apt in many instances, there is a point in the intellectual space where imitation is more akin to theft. This is certainly the case in the higher education sector where, in the internet age, the increasing incidence of student plagiarism has become an ever-increasing cause of concern.

Plagiarism may be defined as the use of another person's words and/or ideas without acknowledging that the ideas and/or words belong to someone else for someone's own benefit. It is not a new phenomenon, but there is little doubt that it is a growing problem that lecturers and universities need to address systematically if the underlying causes, rather than the symptoms, are to be addressed.

The problem is not limited to Economics but given that Economic departments tend to have a significantly higher number of students than other degrees, above average class sizes and a significant proportion of international students, it is arguably more likely to be of especial relevance to economics academics.

At the heart of the problem is not only the increasing availability of easily accessible electronic resources, whereupon it has become so much easier for students to 'cut and paste' slabs of unedited text but it has become much easier to order a complete, bespoke piece of work from one of the many available online providers. This can sometimes lead to assignments being submitted that are inadequately referenced, highly unfocused or, worse still, largely or entirely someone else's work.

This chapter considers the various strategies currently being employed to stamp out plagiarism. These include the use of 'honour codes' that incorporate punitive systems to discredit plagiarists, the various proprietary and freeware packages available for the electronic detection of plagiarism. More importantly it discusses some practical prevention strategies that includes designing and implementing types of assessments that make plagiarism more difficult to take place.

The discussion will concentrate, first of all, on the defining characteristics of plagiarism and how it manifests itself in the current university environment. This is followed by a brief discussion on the factors deemed to be responsible for plagiarism, and the mechanisms subsequently employed by various institutions to deal with its increasing incidence. The discussion concludes by arguing for an integrated approach founded upon a commitment to assessment regimes that reward critical analysis rather than content regurgitation.

To proceed down this path, it is further argued that assessment items need to be designed in such a way as to present students with authentic learning environments: that is, settings for assessment that engage students with real and relevant tasks, with palpable and practical learning outcomes. Of all disciplines, economics is one that readily lends itself to this approach. 
The main aim of the discussion, therefore, is to demonstrate that, while introducing measures to improve deterrence and detection of plagiarism is important, this is essentially a reactionary approach. It is unlikely to yield lasting benefits and might not be efficient to stamp out the most serious types of plagiarism. It is argued that the source of the problem is systemic, and that the focus needs to be on prevention of plagiarism through the use of innovative and engaging assessment. To this end, it is further posited that information and communications technologies (ICTs) can be of invaluable assistance - the very technologies that have led to the burgeoning student plagiarism problem in the first place. 


\section{Plagiarism in Higher Education}

'Plagiarism' derives from the Latin word plagiarius, meaning 'kidnapper' or 'abductor'. It is the theft of someone's creativity, ideas or language; something that strikes at the very heart of academic life. It is a form of cheating and is generally regarded as being morally and ethically unacceptable.

It should not be surprising, therefore, that plagiarism is such an emotionally charged issue and that agreeing on what plagiarism is might not always an easy task, especially when we talk about punishing this practice. Plagiarism can be the result of sloppy referencing, honest errors and different cultural and ethical values with respect to academic work.

Therefore, one key aspect when we deal with plagiarism must be the intent to plagiarize and the fact that intent is not always easy to prove might explain the very small number of students that are punished with expulsion from their universities (see section 2.3).

\section{Top Tips 1}

1. Always ensure that you are familiar with your institution's plagiarism policies and regulations, and be able to explain them in jargon-free terms to the students.

2. Strike an appropriate balance between 'encouragement' of the learning process and the potentially serious consequences if plagiarism is proven.

3. A worthwhile exercise is to spend some time in class (or interactively online) going through real examples of what does and does not constitute acceptable practice. A suggested method of doing this is contained in section $\underline{2.5}$.

\subsection{The different types of plagiarism}

Given the dramatic increase in its incidence, most universities around the world have made a point of including definitive statements on plagiarism in student handbooks and on university websites in the hope that no student standing accused of plagiarism can mount a defence on the grounds of their ignorance[i]. The fact remains, however, that even proceeding on the basis that all students are diligent enough to read the 'fine print' in university policy documents, the scope of plagiarism is such that it incorporates a range of offences not easily defined in the space of a few sentences. In short, there will be instances where the extent of plagiarism is very serious, others when it will be relatively minor, and times when it falls somewhere in between. As a consequence, a range of policy responses is required to match the gravity of the offence.

It is certainly important to send out a clear signal to the student body that plagiarism will not be tolerated, but it is also important to acknowledge the 
possibility of genuine cases of unintentional plagiarism, and to be wary, therefore, of over-zealous policing of plagiarism. In any case, it is essential that the institution be capable of distinguishing between intentional and unintentional plagiarism.

Without wanting to over-generalise, plagiarists may be identified as one of the following three types:

- the lazy plagiarist;

- the cunning plagiarist;

- the accidental plagiarist.

The 'lazy' plagiarist is generally an academically weak and otherwise undermotivated student, the type who would happily take the work of someone else in its entirety, do little more than to change the name on the paper and claim it for their own. This type of student may use the 'cheat sites' or simply steal the work of others - maybe that belonging to a student who studied the subject in a previous year. For this type of plagiarist, if a ready-made answer to a question cannot be found electronically, it simply cannot be worth having. The development of an educated opinion, a lively inquiring mind, a creative impulse: these things are not worthy of consideration. As a student's e-mail signature once read: 'Clay's Conclusion: Creativity is great, but plagiarism is faster'.

For those student plagiarists who elect not to procure work from their colleagues or consume the services of the online paper mills, there is still an abundance of other point-and-click plagiarism opportunities. Plain, old-fashioned laziness is certainly a factor, but internet-inspired indolence has given rise to a more refined form of sloth. The 'cunning' plagiarist is more sophisticated than the lazy plagiarist and takes full advantage of these abundant opportunities: they are quite clear about what plagiarism is, but work hard to avoid detection. Content is cut-and-paste from a variety of sources on the Web (and possibly from other students' papers), with a view to manufacturing an answer. They may also attempt to cover their tracks through the provision of incomplete or inaccurate bibliographic details in their list of references, which make it more difficult to track their misdemeanours (Renard, 1999).

The most sophisticated lazy plagiarist is well versed on the existing plagiarism detection tools (see section 2.3 below) and knows how to avoid detection by, for example, changing every $7^{\text {th }}$ word of the original text so that the automated plagiarism detection software does not pick up the offense[ii].

The 'accidental' plagiarist, by contrast, is not in the least bit devious. Their transgressions arise typically as a consequence of inexperience, poor study skills, local academic norms or some combination thereof. Such students typically insert slabs of unattributed text in their essays and, when challenged, will be either embarrassed by their sloppy referencing or genuinely surprised that they have been challenged at all, claiming ignorance of the system. 
In many instances, it is international students who fall into this latter category, particularly those from East Asian countries. Apart from a lack of exposure to western academic norms when it comes to academic work, these students can sometimes experience difficulty in constructing a critically analytical essay out of cultural respect for those in authority. This is sometimes mistaken for poor writing ability and/or a lack of ethics when the reality might be somewhat different. In Confucian cultures, for example, conventional wisdom is that the best ideas are those of the ancients, and their philosophy and insights are so wide-ranging that to challenge those ideas would be interpreted as quite an audacious act. Instead, memorisation and recitation are valued. It follows that to challenge 'the truths' handed down by 'the sages' who author textbooks and write lecture notes would be counter-cultural for students of this tradition (Smith, 1999).

Not everyone accepts this view, of course, and a standard response is that it should be a case of 'when in Rome do as the Romans do', with students observing the cultural norms of the country in which they are studying rather than those of their home country. Without going into an in-depth discussion of the validity of this argument, it is probably fair to say that first-year students, in particular, might be extended some latitude, at least until they have had an opportunity to commence with the cultural transition and adjust to the different cultural norms.

\section{Top Tips 2}

4. Always be sensitive to cultural differences that may confuse students' understanding of the plagiarism concept, especially those who are new to your country's education system.

5. Encourage students to check with their tutor prior to submission as to whether they may have inadvertently broken (accepted) practice.

In any event, some allowances will have to be made where assignments must be written in a second or third language. This is not to condone wholesale plagiarism; simply to recognise that writing in a foreign language engenders a strong temptation to get linguistic assistance.

Finally, it is also important that the department has a unified position about how to deal with and communicate about plagiarism. On the one hand, the message about plagiarism will be assimilated much faster if all academics use a common language and apply a similar approach on how to deal with plagiarism cases. On the other hand, coordination among academics will help come up with efficient prevention strategies by for example applying a progressive approach to deal with plagiarism (this might include, for example, teaching students about plagiarism by setting an intermediate formative assessment before the summative assessment or allow first year students to view the Turnitin's Similarity Report before submitting the final version of their assessment - see section 2.3). 
[i] Many universities now require students to sign 'student contracts' that include specific regulations on cheating, collusion and plagiarism. For an example see University of Leeds student contract web page http://students.leeds.ac.uk/studentcontract.

[ii] When academics set a Turnitin assignment (see section 2.3), they can set a threshold minimum numbers of words to be picked up by the similarity report. Setting a high limit (say 7 words) will exclude a large amount of sentences that are not of sufficient length from being considered in the similarity report making it much easier and faster to interpret the results.

\subsection{The motivations for plagiarism}

To some, the increasing incidence of plagiarism in the higher education sector (see next section) may be looked upon as perfectly acceptable behaviour. According to author and satirist Stewart Home, plagiarism 'saves time and effort, improves results, and shows considerable initiative on the part of the plagiarist' (cited in Duguid, 1996). This line of thinking is predicated upon the notion that there is nothing sinister about the liberal use of other people's ideas. To plagiarise is not to steal another's property, it is simply about the spread of information and knowledge.

Indeed, prior to the eighteenth-century European Enlightenment, plagiarism was useful in aiding the distribution of ideas and, in this sense, can be said to be an important part of western cultural heritage, up to that point in time. One might argue further that, with the new social conditions that have emerged with the widespread use of ICTs, it has once again become an inevitable part of contemporary culture, although for rather different reasons (Critical Art Ensemble, 1995). Allied to this is the increasingly results-driven education system, with its associated league tables, as well as the increasingly difficult labour market conditions for graduates, resulting from the UK's wider-access policy for higher education.

Taking a more sceptical view, if we accept that it is typically the academically weaker students who tend to engage in the various forms of plagiarism, it is unlikely that these individuals will, consciously or unconsciously, be part of any crusade to spread information and knowledge. On the other hand, as the statistics cited in the next section would tend to indicate, it cannot be just they who are indulging in unethical practice (unless the majority of students can be described as academically weak!). Why is it, then, that students are resorting to plagiarism in increasingly large numbers?

Irrespective of a student's ability, pressure to plagiarise can emerge because of a variety of influences. These include, for example:

- poor time management skills (a problem often exacerbated because of the increasing competition for students' time arising from the need to work part 
time or care for children) and an inability to cope with workload (perhaps as a result of class timetables and the corresponding multiple assessment tasks, with submission deadlines often bunched around the same date);

- a lack of motivation to excel because of a perception that the academic responsible for the class has little enthusiasm for the subject (the students then expending what they consider to be a commensurate amount of effort);

- increased external pressure to succeed from parents or peers, or for financial reasons;

- an innate desire to take on and test the system (particularly if the punishment associated with detection is relatively minor);

- cultural difference in learning and presentation styles where, in some settings, it is considered normal custom and practice to quote the experts without citation (Joint Information Systems Committee, 2003).

This is by no means an exhaustive list of the factors that might be considered responsible for the frequency of plagiarism; suffice to say that it is an indicator of the complexity of the issue. Neither do these factors necessarily explain the increasing incidence of plagiarism. Indeed, many, if not all, of those reasons listed above were in existence prior to the dramatic increase in the number of reported cases of plagiarism. The key explanatory variable, it would seem, is the increasing availability of electronic text. It is this, coupled with any of the above motivations that has spawned the seemingly inexorable rise in student plagiarism.

\section{Top Tips 3}

6. Ensure that assessment construction minimises the ease with which plagiarism can be both difficult to resist by the student and difficult for staff to detect (see section 2.5).

7. Be flexible in allowing extensions to deadlines if you are convinced that the only alternative would be to receive a plagiarised submission.

8. Overall, consider co-ordinating the timing of assignments in conjunction with other subjects, with a view to avoiding 'peak loading'.

The spate of books on the subject, along with the various websites, media reports, conferences and symposia, is testimony to the amount of intellectual energy currently being dedicated to the topic of internet plagiarism. The major preoccupation is with both detection and deterrence: detection by resorting to 'fighting fire with fire' using various proprietary and freeware anti-plagiarism packages; deterrence through stressing the importance of education in ethics to ensure that students are not tempted to breach their university honour codes, and through the meting out of stiff penalties to offenders, to send a clear message that plagiarism is behaviour not to be tolerated in any circumstances.

\subsection{A 'plagiarism epidemic'}


If evidence is required of the alarming rise in the incidence of plagiarism, we just have to turn some recent reports in the media. A recent article in The

Times (January 2, 2016) reported, in an investigation based on more than 100 freedom of information requests, that almost 50,000 students at British Universities were caught cheating over the previous three years. The article also reported a number of other important findings:

- Non-EU overseas students made a disproportionate number of the students caught cheating (Of the 70 universities that provided data from overseas students, those students were involved in $35 \%$ of all cheating cases but made up just $12 \%$ of the student body)

- The problem is not limited to undergraduate studies. Almost $20 \mathrm{PhD}$ students (or equivalent) were disciplined for academic misconduct over the previous three-year period.

- 5 cases of impersonation were recorded at one university alone.

- Only about $1 \%$ of those found guilty of misconduct were dismissed because of cheating.

- "Freelance academics" charge anything from $£ 10$ to $£ 20,000$ for coursework answers, dissertations and even an '80,000-word $\mathrm{PhD}$ '

This media article led to a very quick response by the Quality Assurance Agency for Higher Education (QAA), the independent body that checks on standards and quality in UK higher education with several policy documents produced in quick succession. First, in February 2016 the QAA Viewpoint alerted universities to the issues of 'paper mills' (QAA (2016a)), a few months later, in August a full report on custom essay writing services was published on the issue (QAA (2016b)) and in October 2017 produce a comprehensive guidance document for HE providers (QAA (2017)).

A recent article by Rigby at al. (2015) developed the first empirical investigation of the decision to cheat by university students and found that risk preferring students, those working in a non-native language, and those believing they will attain a lower grade are willing to pay more for an essay and hence are more likely to plagiarize. Furthermore, and perhaps not surprisingly, they also found that the likelihood of a student purchasing an essay and the amount a student is willing to pay for those essays decline as the probability of detection and associated penalty increase. This result partly explains the high incidence of plagiarism found in The Times (2016) article. The fact that only $1 \%$ of the students caught cheating were expelled from their universities might lead students to believe that, in what concerns plagiarism, crime pays in the end.

The high number of reported cases of plagiarism detected by universities are only made possible by the widespread use of plagiarism detecting software tools, the most widely used of which is Turnitin.

Turnitin is a Web-based platform for management of assignments and feedback, with a built-in check for plagiarism and collusion. It compares each assignment 
with its database of " +45 billion web pages, $337+$ million student papers and $130+$ million articles from academic books and publications" [i]. For that reason, it is a very effective and powerful tool to prevent collusion among students within the same university, the 'recycling' of parts or the totality of papers by students in different modules, students 'sharing' the same paper at different universities and the outright copy and paste plagiarism from materials available online.

Figure 1 below shows an example of an originality report.

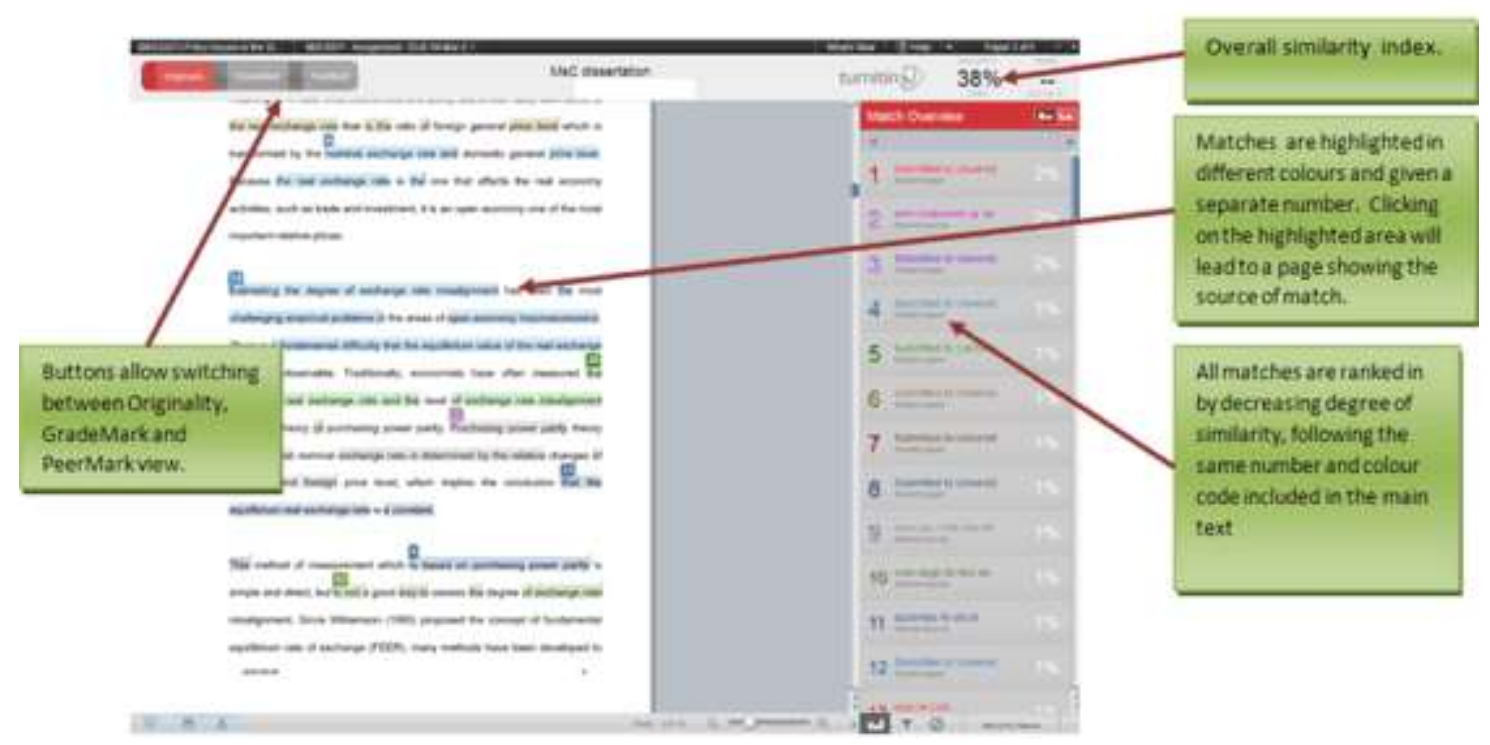

Figure 1: Example of originality report in Turnitin (click to expand)

Detecting plagiarism using Turnitin can be very time consuming and complex[ii]. A high similarity score does not immediately imply that plagiarism or collusion was committed as it can be the result of the sum of many similarity matches of small, commonly used expressions. Another complication is that the software can be manipulated by students if they are allowed to see their similarity reports and resubmit their work by, for example, changing the occasional word in a sentence to make the software filters ignore the similarity. Allowing students to see the originality report in their work prior to submission can be a very useful tool to teach students about plagiarism as well as safeguard academic integrity but this is not without its dangers.

Figure 2 shows an example of plagiarism in Turnitin. Although many small similarities with other work are found, which is to be expected, there is one match that accounts for a very large amount of similarity (38\%) and most of this comes from entire paragraphs being copied and pasted directly into the assignment. Further investigation (as well as proof of the plagiarism) can easily be made by clicking on each match on the match overview panel, which will take you to the original source of the text. Sometimes that source is not publicly available (e.g. paper submitted by a student at another university) and in these cases the academic will need to ask for permission request to the author's instructor to see the original paper. 


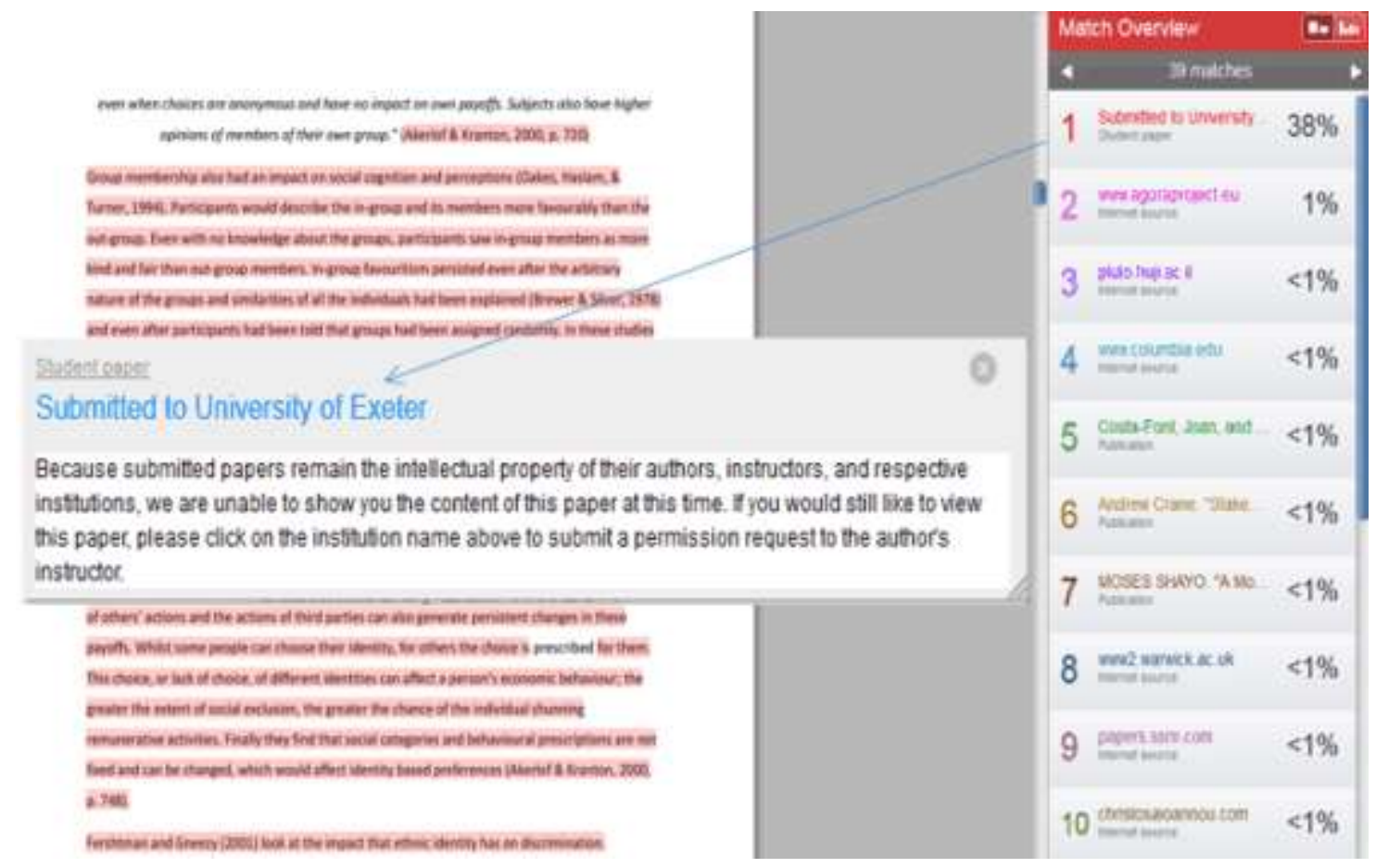

Figure 2: Example of plagiarism in Turnitin (click to expand)

[i] Source: http://www.turnitinuk.com/en_gb/features/originalitycheck/content

[ii] Turnitin has recently introduced a new system, which they called 'Feedback Studio'. Although the layout changed slightly with the introduction of 'layers', the functionalities available remain the same.

\subsection{The tip of the Iceberg? The 'Paper Mills' problem}

Plagiarism detection, with software tools like Turnitin, is used widely at British universities and extremely useful in detecting what can be called 'type-1 plagiarism' [i]: the act of copying and pasting materials available online. These applications seem impotent, however, to detect Type-2 plagiarism or the use of bespoke essay-writing services or 'essay mills' - businesses that make up arguably one of the most successful internet industries after pornography and gambling. Indeed, as The Economist observed in the aftermath of the dotcom crash, these cheat sites are one of the few dotcom business models that continue to prosper (Anon., 2002).

Some sites rely on advertising revenue and supply services free-of-charge or facilitate exchange (students submitting a paper and getting one in return). In most cases, however, it is fee-for-service. Students can purchase pre-written or commissioned papers, and while the format varies slightly from one operator to another, customers can pay anywhere from "several hundred pounds for a single essay to $£ 6,750$ for a PhD dissertation" (Khomami (2017)). 
The most professionally looking UK-based sites, like for example, oxbridgeessays.com or ivoryresearch.com, offer a very wide variety of products for students at every level of study.

Figure 3 below shows an example where clients can choose from different levels of study from A-Levels to Postgraduate studies (help with " $\mathrm{PhD}$ proposal, title creation or individual chapters" of a $\mathrm{PhD}$ dissertation are also available but require speaking to an 'academic consultant') and a drop down menu choice of specialized topics within each discipline.
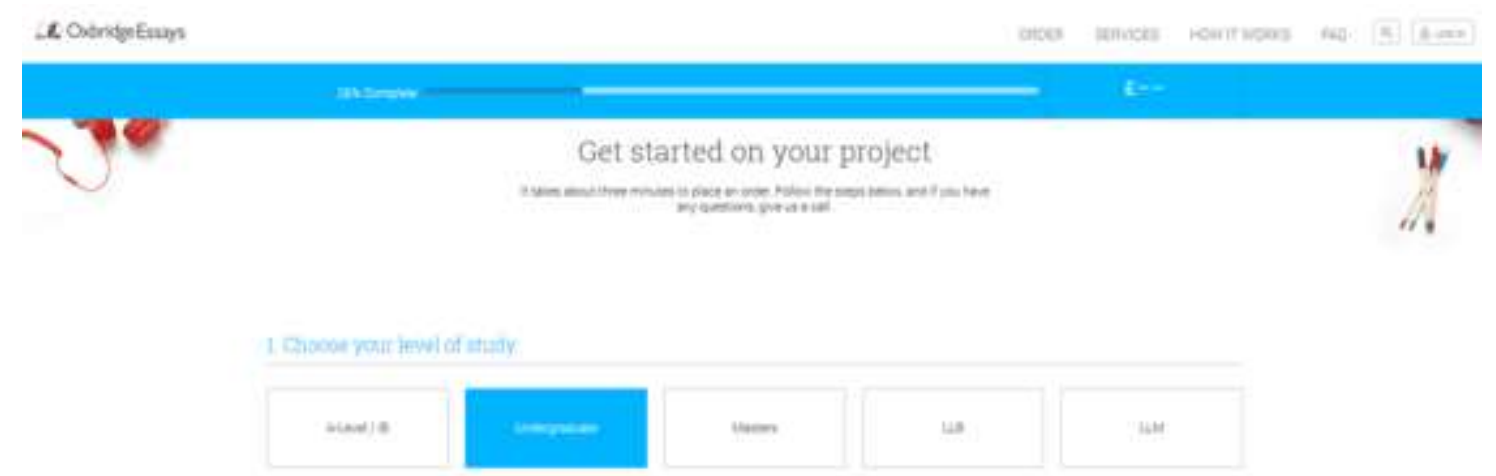

Figure 3: Booking a 'Project' (click to enlarge)

Although these type of companies invariably have a disclaimer that their products are "intended solely for the purpose of inspiring that client's own work through giving an example of model research, writing, expression and structuring of ideas" (OxbridgeEssays, terms and conditions), it is clear that the business model is directed at providing students with " $100 \%$ original and plagiarism Free" papers.

Figure 4 shows the options available to clients when booking a project. The variety of types of products is amazingly large and clients can buy bespoke pieces of work that include not just essays and full dissertations but also presentations, dissertation proposal, literature reviews, critical reviews, among others.

Clients can even specify what grade boundary they are after (from 2:2 to 'Upper $\left.1^{\text {st' }}\right)$, chose the date of delivery in an airline-style booking site where prices change according to the date of delivery, have a 'money back guarantee' (e.g. UKessays.com) and generous discounts (e.g. BuyEssays.co.uk provided a 20\% discount to all customers at the time of writing this chapter). 
The example presented in Figure 4, shows the prices for a full undergraduate dissertation, for a 'standard 2:1 (60-64\%) over a month period. Depending on the urgency prices over that period vary from $£ 245$ ( 3 days) to $£ 160$ (90 days). If the grade boundary is instead chosen to be 'Upper $1^{\text {st }}\left(75 \%{ }^{+}\right)$' the prices range from $£ 525$ (3 days) to $£ 345$ (90 days).

The providers link clients to writers that are recent graduates from the same or similar institutions or even a "network of some of the finest academic writers in the UK and beyond" (OxbridgeEssays.com, How it Works) and therefore are very familiar with the each university's requirements for assessment.
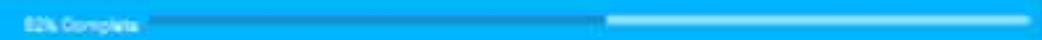

3. Work required
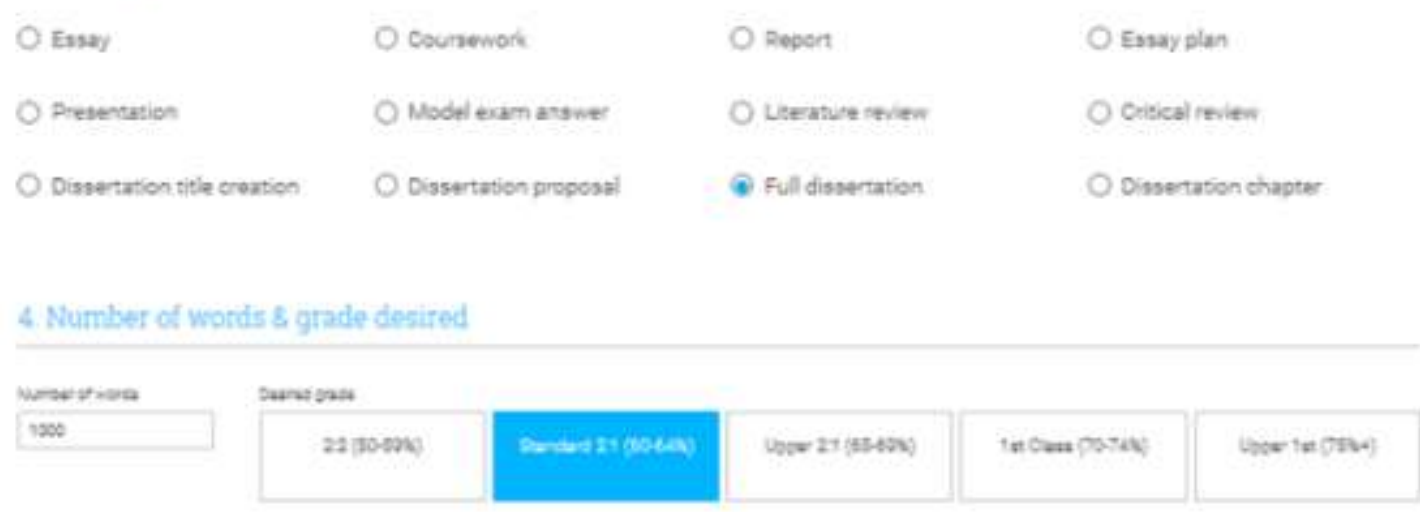

\begin{tabular}{|c|c|c|c|c|c|c|}
\hline tenty & moser & worose & 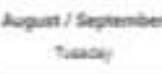 & nerms, & Doncer & mas: \\
\hline 5 & & $\frac{7}{7}$ & 8 & 9 & 10 & $\begin{array}{l}11 \\
\text { nat }\end{array}$ \\
\hline 12 & 13 & 14 & 15 & 16 & 17 & 18 \\
\hline 19 & 20 & 21 & 22 & 23 & 24 & 25 \\
\hline 26 & $\frac{\pi}{27}$ & 28 & 29 & 30 & 31 & 1 \\
\hline 2 & & 60 Days & 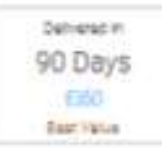 & & & \\
\hline
\end{tabular}

Figure 4: Choosing a delivery date and a classification (click to enlarge) 
The service also typically includes 'Upgrade Options'. Figure 5 shows an example where clients can ask for alterations (from a standard 10 days for an additional $£ 16$ to an unlimited alterations period for an additional £64), an 'essay development plan' that explains in detail "how the academic produced your model 'essay' with a clear breakdown of how you are able to further develop the work from their guidance." A 'revision guide' is also available that provides "additional revision sheets summarising the topics and arguments covered within your delivered work." all of which would, arguably, be invaluable if the client was asked to give a presentation or a viva.

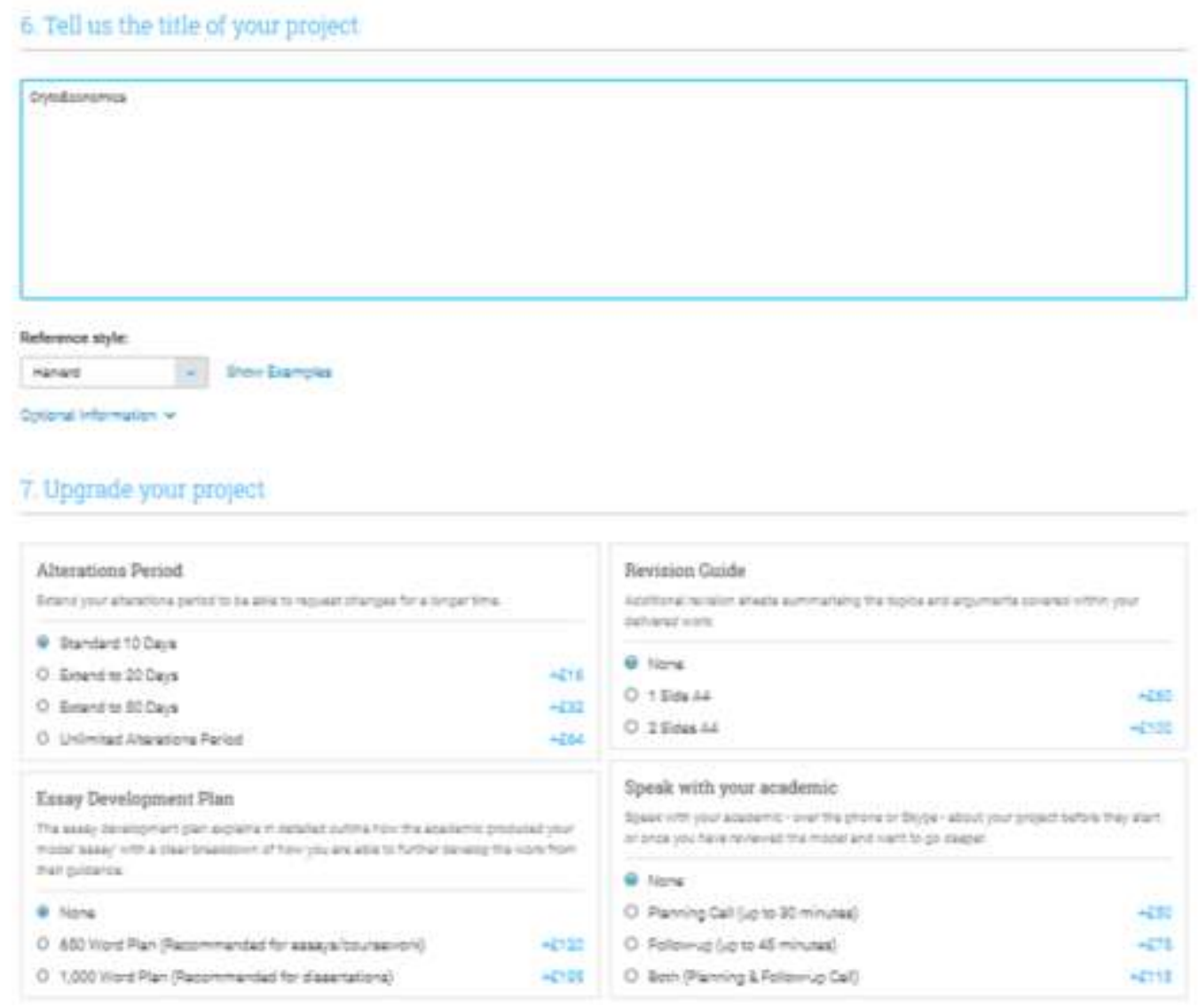

Figure 5: Some Upgrade Options (click to enlarge)

While accurate statistics are not always easy to obtain given the dynamism of the industry, cursory perusal of the websites of the leading companies would suggest that, taken together, these sites are likely to receive visitor numbers running into millions each week. StudyMode.com, for example, a company founded in 1999 boasts that it is "self-funded and expanding daily, (...) serves more than 2 billion pages per year to students all over the world."

The growth in this industry is surprising given the lack of guarantees clients get. If a client finds herself out of pocket because the company fails to supply the order or gets a grade that is lower than the one she paid for, it will be hard to complain without exposing herself as a cheat. 
"[O]nline forums are full of complaints about essays arriving peppered with spelling mistakes, arguments that don't match pre-approved propositions and - the most common grievance - results that don't match the promised grade." Potts $\underline{(2012)}$

Potts (2012) reports one of those cases where a client did not receive her essay on time and was informed by the supplier that she could not get a refund but could claim a discount off the next purchase she made with them. The essay never arrived and she was $£ 200$ out of pocket.

Given these developments, it is not surprising that a large volume of literature has emerged in the last few years focusing on the subject of plagiarism in the higher education sector. The rise of 'paper mills' seems to be increasing plagiarism to truly epidemic proportions, raising serious concerns among universities and governments.

The UK universities minister Jo Johnson stated recently that "this form of cheating is unacceptable and pernicious. It not only undermines standards in our world-class universities, but devalues the hard-earned qualifications of those who don't cheat". He urged the sector to implement "strong policies and sanctions to address this important issue in the most robust way possible"[ii].

[i] The terms type- 1 and type-2 plagiarism were assigned to Geoffrey Alderman of the University of Buckingham in The Times (2016) article.

[ii] http://www.qaa.ac.uk/newsroom/cheating-in-higher-education-new-guidanceon-prevention

\subsection{Deterring and preventing 'Type-2' plagiarism}

Various strategies can be employed by academics to police plagiarism, ranging from simple Web search techniques used by individual lecturers, to the employment of easy-to-use freeware capable of tracking plagiarism between cohorts of students, as well as to quite elaborate systemic approaches involving the engagement of commercial plagiarism detection companies as described in section 2.4 .

Detecting type-2 plagiarism, the production of bespoke essays by professional staff, is a much harder, time consuming task and very difficult to prove in most cases. As discussed above, 'paper mills' employ experienced professionals (in fact, some paper mills boast having established academics working for them) to produce tailored and completely original work which for that reason is not detectable via the plagiarism detection software. Academics might find themselves reading assignments that are out-of-character for a specific student (because the quality of work is higher than the typical grades the student gets, or the assignment uses 
colloquialisms that are unlikely to be known of certain groups of students) but given that the academic has burden of proof, the punishment of this practice might not always be forthcoming.

This explains why in recent years, the attention seems to be turning to developing software applications that detect plagiarism through the use of stylometry - the application of the study of linguistic style to determine the authorship of (mostly written) works. Software applications that use stylometric analysis basically study measurable features of literary style, such as sentence length, vocabulary richness and use statistical tools to identify variations in the frequency of words, word lengths, word forms, that suggest different authorship and hence plagiarism. Although these products are still in a developing stage, academics are very hopeful that these applications will assist with the detection of completely plagiarized works, bought from Paper Mills [i].

\section{Top Tips 4}

9. Familiarise yourself with the various plagiarism detection software packages and develop an efficient rubric for checking your submissions.

10. Consider forming detection 'teams' with a view to providing an efficient division of labour and guidelines for best practice.

\section{Remain open-minded at all times.}

While most universities around the world rely on their publicly stated policies and procedures (including honour codes and student contracts) to act as a deterrent to any student contemplating plagiarism, their publication alone is unlikely to cut any sway with would-be plagiarists. Even universities that are committed to eradicate plagiarism must be aware that approaches that "focus on eradication rather than minimisation of plagiarism can be impractical, prohibitively expensive and even harmful to the learning environment" (QAA (2017)).

Given that chances of detection of type-2 plagiarism are painfully low (as evidenced by the extremely low rates of punishment - see section 2.3), the way to avoid type- 2 plagiarism must be through prevention.

Prevention may be associated with the creation of an environment where students never feel motivated to plagiarise or where engaging in plagiarism becomes very costly and extremely difficult, making it a less attractive practice to engage on.

\section{Top Tips 5}

12. Create an explicit focus on learning outcomes - students need to see the point of what they are doing.

13. Design assessments that motivate students on the basis of the quality of their learning and the generic skills they acquire rather than the content they memorise. 
14. Design assessments where the learning experience is truly authentic, suitably contextualised, completed within a suitably limited time period and as specific to the university course unit as possible.

15. Encourage students to role-play and 'suspend disbelief' in assignments, so that they develop a much greater empathy for the subject matter (Chancellor of the Exchequer, CEO, etc.).

16. Include the mandatory use of assignment cover sheets that incorporate signed declarations of originality.

17. With an assignment that is to be submitted electronically, use pop-up confirmations about the conditions that a student is agreeing to when they upload their assignment.

The ability to analyse problems critically is not in abundance among those who elect to plagiarise material from the internet or from their peers, and as the discussion in the sections above demonstrates, the policing of this kind of activity can be a time-consuming and expensive business.

Formal tuition in the art of critical thinking is certainly a way forward, but this will not be time well spent if, subsequently, students are not presented with adequate opportunity to apply this important generic skill. All too often, assignments and examination questions are set that encourage the reproduction of content knowledge rather than critical appreciation of that content knowledge. Generally speaking, this tends to be a reflection of module design that is driven primarily by content considerations and where assessment is very much of an afterthought, rather than the other way around. In short, to be effective, assessment must be authentic: it must mean something to the student, so it will engage them and add value to their skill set.

As scholars such as Ramsden (1992) have argued, the quality of students' understanding is intimately related to the quality of their engagement with learning tasks. Setting tasks that test their memories or their ability to reproduce content material is not particularly engaging, and this is precisely what many assessment items require - the same assessment items that, coincidentally, lend themselves very well to cutting-and-pasting techniques.

A pertinent question to ask is whether students are entirely to blame for the plagiarism problem that plagues our universities. The study conducted by Ashworth et al. (1997) would suggest not. They conclude that cheating might be looked upon as a symptom of some general malaise. They found that students felt alienated from teaching staff because of their demeanour and their lack of contact with students. Assessment tasks that fail to engage students are a symbol of this gap between students and lecturers, and in the absence of any basic commitment on the part of the student that the work they are doing is significant, there is no moral imperative to refrain from plagiarism or cheating. 


\section{Top Tips 6}

18. Exercise a firm commitment to authentic assessments that have the effect of minimising the extent of assignment recycling, even to the point where every assessment item is unique.

19. Use a mixture of assessment methods and develop novel, employer-focused types of assessment (e.g. policy briefs, executive summaries, video presentations, etc).

20. Seek to encourage departmental co-ordination in a commitment to authentic assessment as a strategy to combat student plagiarism. In this way, students can see there is a synchronised departmental effort to change the way that learning is assessed, and that there is consistency of treatment when it comes to meting out penalties for plagiarism offences.

The point is that while one cannot 'turn a blind eye' to students' plagiarism, it would be fatuous to assume that it is the students who are at fault and the students alone. Could it be that students are cheating because they do not value the opportunity of learning in university classes? Is it conceivable that the pedagogy currently employed has not adjusted to contemporary circumstances? As one author has observed, 'we expect authentic writing from our students, yet we do not write authentic assignments for them' (Howard, 2002). It is worth considering why this might be so: one argument is that the ever-increasing pressure on academics to teach, research and administer reduces the time for creating imaginative and otherwise difficult-to-plagiarise (for example, individualised) assignments. As a consequence, there is much anecdotal evidence that academics are retreating back to the unseen, written examination as the sole method of assessing student performance in their courses.

As the literature on authentic assessment reveals, it is solidly based on constructivism, and acknowledges the learner as the chief architect of knowledge building (see, for example, Herrington and Herrington, 1998). It is a form of assessment that fosters understanding of learning processes in terms of real-life performance as opposed to a display of inert knowledge. The student is presented with real-world challenges that require them to apply their relevant skills and knowledge, rather than select from predetermined options, as is the case with multiple-choice tests, for example. Importantly, it is an approach that engages students because the task is something for which they will have an empathy, which, as the empirical evidence suggests, elicits deeper learning.

The key, therefore, is to set meaningful, situational questions relating to real-life, contemporary problems that engage students in the learning process. By making assignments as module-specific as possible - to prevent students from purchasing pre-written papers or paying outsiders to write answers and by the examiners making it clear (as a stated objective of the module unit) that they are looking to 
reward evidence of depth of learning and sound critical analysis rather than recall of content knowledge - assignments are effectively cheat-proofed, although we must always be mindful of the increasing resource constraints placed upon academics.

\section{Top Tips 7}

21. Make it a requirement of assessment submissions that outlines and first drafts be submitted on specified dates in the lead-up to the final submission date. This means that the process of producing an assignment is evaluated as well as the final product (Carroll, 2002). This may not prevent some students copying from one another along the way, but it will thwart those individuals who look to produce the finished product while doing very little work themselves.

22. Require students to submit a reflective journal describing their approach to the task, the methodology adopted, the problems encountered and how they resolved these problems.

23. Hold random viva voce sessions that require students to defend and further explain, if necessary, what they have written. If this is clearly advertised to students in class and in course documentation, it will serve as an effective deterrent.

Something of a paradigm shift is likely to be required if the changes described above are to be readily embraced by the majority of teachers in the higher education sector. However, it is worth mentioning that the various ICTs, used effectively, may well assist in this endeavour. Indeed, one could make the point that if as much energy and ingenuity went into developing new and exciting online devices for the purposes of facilitating assessment as there have been devoted to online devices for the detection of plagiarism, then maybe there would be fewer obstacles to negotiate.

In summary, while there is clearly a need to allocate some resources to detection and deterrence, these are essentially reactionary strategies with low probability of success. The proactive measure is the prevention of plagiarism through innovative pedagogy, as this is more likely to produce lasting results. Such an approach provides students with an incentive to learn. The natural corollary to this is that there will be less incentive for students to resort to plagiarism.

[i] Software applications that use stylometry to detect plagiarism include JGAAP, AICBT and Signature. 


\section{Further Reading}

Austin, M. and Brown, L. (1999) 'Internet Plagiarism: developing strategies to curb student academic dishonesty', The Internet and Higher Education, vol. 2, no. 1, pp. 21-33. DOI 10.1016/S1096-7516(99)00004-4

Bannister, P. and Ashworth, P. (1998) 'Four good reasons for cheating and plagiarism', in C. Rust (ed.), Improving Student Learning Symposium, Centre for Staff Development, Oxford Brookes University, Oxford.

Carroll, J. (2002) A Handbook for Deterring Plagiarism in Higher Education, OCSLD, Oxford Brookes University, Oxford.

Furedi, F. (2001) 'Cheater's Charter', Times Higher Education Supplement, 8th June 2001.

Oblinger, D., Groark, M. and Choa, M. (2001) 'Term paper mills, anti-plagiarism tools, and academic integrity', Educause Review, vol. 36, no. 5, pp. 40-8.

Harris, R. A. (2001) The Plagiarism Handbook: Strategies for Preventing, Detecting and Dealing with Plagiarism, Pyrczak Publishing, Los Angeles, CA.

Herrington, J. and Herrington, A. (1998) 'Authentic assessment and multimedia: how university students respond to a model of authentic assessment', Higher Education Research and Development, vol. 17, no. 3, pp. 30522. DOI 10.1080/0729436980170304

Moon, J. (1999), 'How to stop students from cheating', Times Higher Education Supplement, 3rd September 1999.

Lathrop, A. and Foss, K. (2000) Student Cheating and Plagiarism in the Internet Era: A Wake-up Call, Libraries Unlimited, Englewood, NJ.

Newton, P. and Lang, C. (2016) Custom Essay Writers, Freelancers, and Other Paid Third Parties, in T. Bretag (ed.) Handbook of Academic Integrity, Singapore: Springer Singapore, pp. 249-271.

Park, C. (2003) 'In other (people's) words: plagiarism by university students literature and lessons', Assessment \& Evaluation in Higher Education, vol. 28, no. 5, pp. 471-88. DOI $\underline{10.1080 / 02602930301677}$

Wiggins, G. (1990) 'The case for authentic assessment', Practical Assessment, Research \& Evaluation, vol. 2, no. 2, online

at http://PAREonline.net/getvn.asp? $\mathrm{v}=2 \& \mathrm{n}=2$ (last accessed 12 June 2004). 


\section{References}

Anon. (2002) 'Plagiarise: let no one else's work evade your eyes', The Economist, online at http://economist.com/PrinterFriendly.cfm?Story ID=1033832 (last accessed 12 June 2004).

Ashworth, P., Bannister, P. and Thorne, P. (1997) 'Guilty in whose eyes? Ashworth University students' perception of cheating and plagiarism in academic work and assessment', Studies in Higher Education, vol. 22, no. 2, pp. 187-203.

Carroll, J. (2002) A Handbook for Deterring Plagiarism in Higher Education, OCSLD, Oxford Brookes University, Oxford.

Critical Art Ensemble (1995) Utopian Plagiarism, Hypertextuality, and Electronic Cultural Production, online at http://college.hmco.com/english/amore/demo/ch5 r4.html (last accessed 12 June 2004).

Duguid, B. (1996) 'The unacceptable face of plagiarism?', online at http://media.hyperreal.org/zines/est/articles/plagiari.html (last accessed 12 June 2004).

Herrington, J. and Herrington, A. (1998) 'Authentic assessment and multimedia: how university students respond to a model of authentic assessment', Higher Education Research and Development, vol. 17, no. 3, pp. 305-

22. DOI 10.1080/0729436980170304

Howard, R. M. (2002) 'Don't police plagiarism: just teach!', Education Digest, vol. 67 , no. 5, pp. 46-9.

Joint Information Systems Committee (JISC) (2003) 'Why do students plagiarise?', online at http://www.jisc.ac.uk/index.cfm?name=plagiarism why (last accessed 12 June 2004).

Khomami, N. (2017) 'Plan to crack down on websites selling essays to students announced', The Guardian, 21 February, online at https://www.theguardian.com/education/2017/feb/21/plan-to-crack-down-onwebsites-selling-essays-to-students-announced (last accessed 4 August 2017)

Potts, M. (2012) “Who writes your essays?”, The Guardian, 6 February, online at https://www.theguardian.com/education/mortarboard/2012/feb/06/essay-writingfor-students (last accessed 15 December 2017)

QAA (2016a), QAA Viewpoint - Plagiarism in UK Higher Education, February, online at http://www.qaa.ac.uk/en/Publications/Documents/QAA-ViewpointPlagiarism-2016.pdf 
QAA (2016b), "Plagiarism in Higher Education - Custom essay writing services: an exploration and next steps for the UK higher education sector", August, online at http://www.qaa.ac.uk/en/Publications/Documents/Plagiarism-in-HigherEducation-2016.pdf

QAA (2017), "Contracting to Cheat in Higher Education - How to Address Contract Cheating, the Use of Third-Party Services and Essay Mills", October, online at http://www.qaa.ac.uk/publications/information-andguidance/publication/?PubID $=3200$

Ramsden, P. (1992) Learning to Teach in Higher Education, Routledge, London.

Renard, L. (1999) 'Cut and paste 101: plagiarism and the net', Educational Leadership, vol. 57, no. 4, pp. 38-42.

Rigby, D., Burton, M., Balcombe, K., Bateman, I. and Abay Mulatu (2015), 'Contract cheating \& the market in essays', Journal of Economic Behavior \& Organization, vol. 111, pp. 23-37. DOI 10.1016/j.jebo.2014.12.019.

Smith, D. (1999) 'Supervising NESB students from Confucian educational cultures', in Y. Ryan and O. Zuber-Skerritt (eds), Supervising Postgraduates from Non-English-speaking Backgrounds, SRHE and Open University Press, Buckingham.

The Times (2016) 'Universities face student cheating crisis', January 2, available at: https://www.thetimes.co.uk/article/universities-face-student-cheating-crisis9jt6ncd9vz7 